\title{
Tracheal Leiomyoma: A Rare Entity \& Role of Diode Laser in Its Management
}

\author{
Anoop Attakkil, Vandana Thorawade, Mohan Jagade, Rajesh Kar, Kartik Parelkar, \\ Dnyaneswar Rohe, Rohini Kashide, Poonam Khairnar \\ Department of ENT, Grant Medical College \& Sir J.J. Hospital, Mumbai, India \\ Email: fasttrack2317@gmail.com
}

Received 20 April 2014; revised 18 May 2014; accepted 15 June 2014

Copyright @ 2014 by authors and Scientific Research Publishing Inc.

This work is licensed under the Creative Commons Attribution International License (CC BY). http://creativecommons.org/licenses/by/4.0/

(c) (i) Open Access

\begin{abstract}
Primary leiomyoma of the trachea is a rare disease which is of smooth muscle in origin. Presenting symptoms depend on the location and size of the tumor. Here we are presenting a 45-year-old female, who was misdiagnosed and being treated for bronchial asthma presented to our institution with stridor. Her x-ray and Computed Tomography of neck showed tracheal mass \& biopsy reported leiomyoma. Objective of this presentation is to report tracheal leiomyoma which is a rare clinical entity and how endoscopic resection of the tumor with diode laser helped us in attaining complete resection of tumor with minimal intra-operative and post-operative complications.
\end{abstract}

\section{Keywords}

\section{Leiomyoma, Diode Laser, Trachea}

\section{Introduction}

Airway tumors involving the trachea are rare with a morbidity of 0.04/100,000 [1] with $90 \%$ of those being malignant [2]. Tracheal leiomyomas account for approximately 1\% or all tracheal tumors, [2]-[5] thought to arise from either smooth muscle fibres surrounding the airway or smooth muscle fibres in blood vessels. Though benign entity, usually are diagnosed late as they are commonly mistaken for obstructive air way diseases.

Cough, wheezing and dyspnoea on exertion are the most common presenting complaints depending on the location and size of the tumor [6]. Surgical excision is the treatment of choice. Different approaches such as tracheal sleeve resection, canal resection, endoscopic resection, electrocoagulation, cryotherapy, and Nd:YAG laser ablation [7] [8] have been reported. We hereby report a case of tracheal leiomyoma, a rare entity with review of the literature. Through this presentation, we intend to focus on the advantages of diode laser that helped us in attaining complete resection of tumor and intaoperative hemostasis with minimal damage to trachea.

How to cite this paper: Attakkil, A., Thorawade, V., Jagade, M., Kar, R., Parelkar, K., Rohe, D., Kashide, R. and Khairnar, P. (2014) Tracheal Leiomyoma: A Rare Entity \& Role of Diode Laser in Its Management. International Journal of Otolaryngology and Head \& Neck Surgery, 3, 143-148. http://dx.doi.org/10.4236/ijohns.2014.34027 


\section{Case Report}

A 45-year-old female came with c/o difficulty in breathing \& noisy breathing since 2 years more while sleeping. She had been managed by physicians for 1year with inhaled corticosteroids and beta2-agonists as a case of asthma. Her indirect laryngoscopic examination was normal. X-ray neck lateral view showed intraluminal soft tissue opacity arising from posterior wall of trachea at the level of C6 - C7 intervertebral disk space (Figure 1).

Contrast Enhanced Computed Tomography of the neck showed $9 \times 11 \times 9$ mm [anteroposterior $\times$ transverse $\times$ craniocaudal] polypoidal growth in posterior wall of upper trachea, $4.5 \mathrm{~cm}$ distal to epiglottis protruding into the lumen causing approximately 60\% luminal compromise with tiny focus of calcification (Figure 2). A low tracheostomy was performed under local anaesthesia as orotracheal intubation was not possible. Biopsy was taken by bronchoscope which reported as leiomyoma.

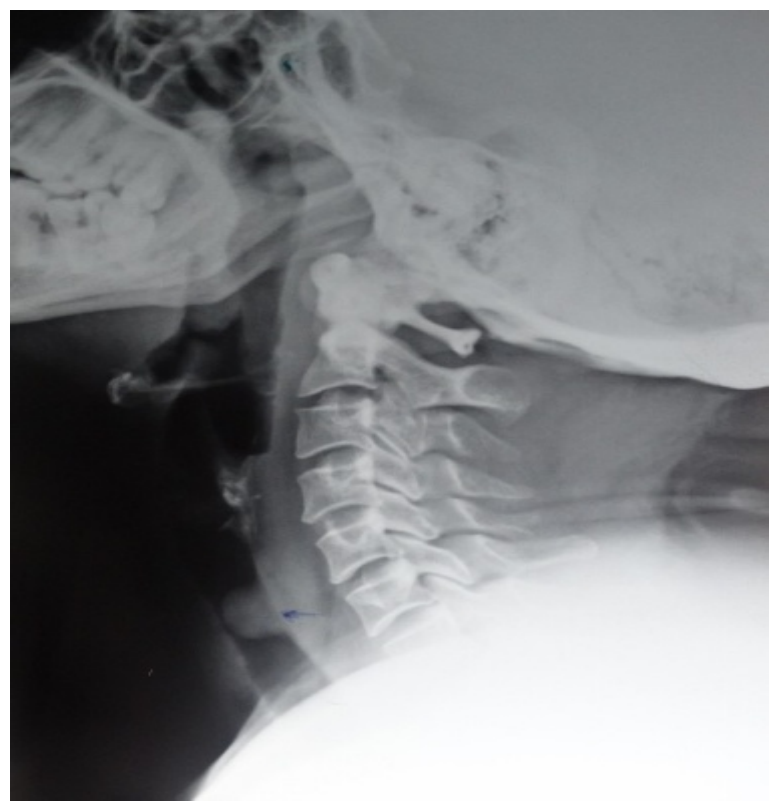

Figure 1. X-ray neck lateral view showing the location of the mass.

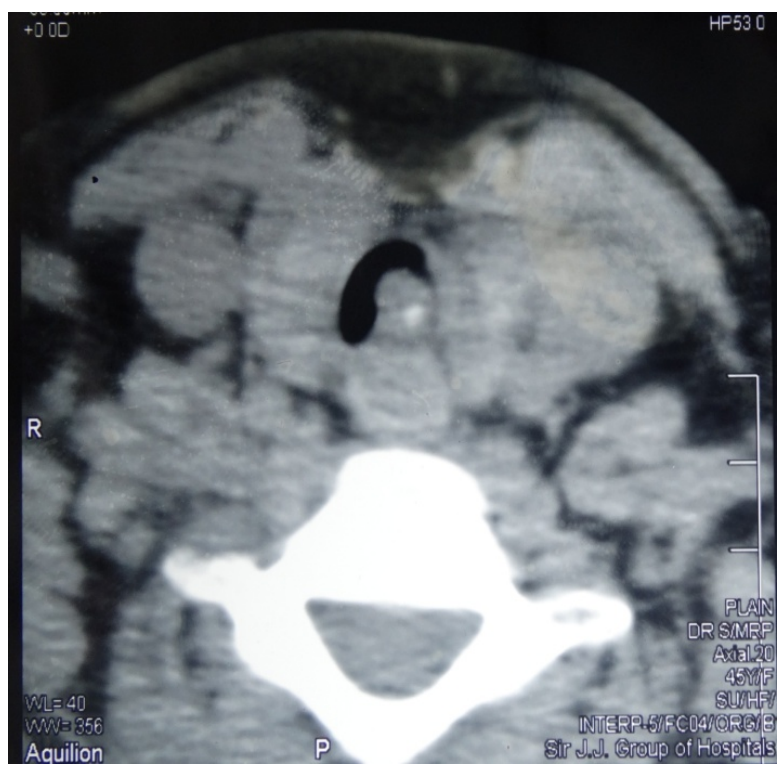

Figure 2. Axial view showing the luminal compromise. 
Patient was then posted for endoscopic resection with diode laser under general anaesthesia. Rigid bronchoscopy showed a smooth, firm, broad-based mass originating from the membranous trachea protruding into the lumen (Figure 3). Diode laser was introduced. Excision was done with diode laser preserving the posterior tracheal wall (Figure 4). Bleeding was minimal. Patient was successfully decannulated on post operative day 3 with no sign or symptoms of respiratory distress.

Macroscopically tumor was well encapsulated measuring $15 \times 8 \mathrm{~mm}$ (Figure 5). Final histopathology report was leiomyoma. Microscopically it showed fragments of neoplasm focally lined by respiratory epithelium. The tumour was composed of intersecting fascicles of spindle cells with eosinophilic cytoplasm and oval to elongated band appearing nuclei with no evidence of malignancy (Figure 6). Patient is on regular follow up for last 6 months. Her bronchosopy revealed well healed trachea without any recurrence of primary lesion or tracheal stenosis.

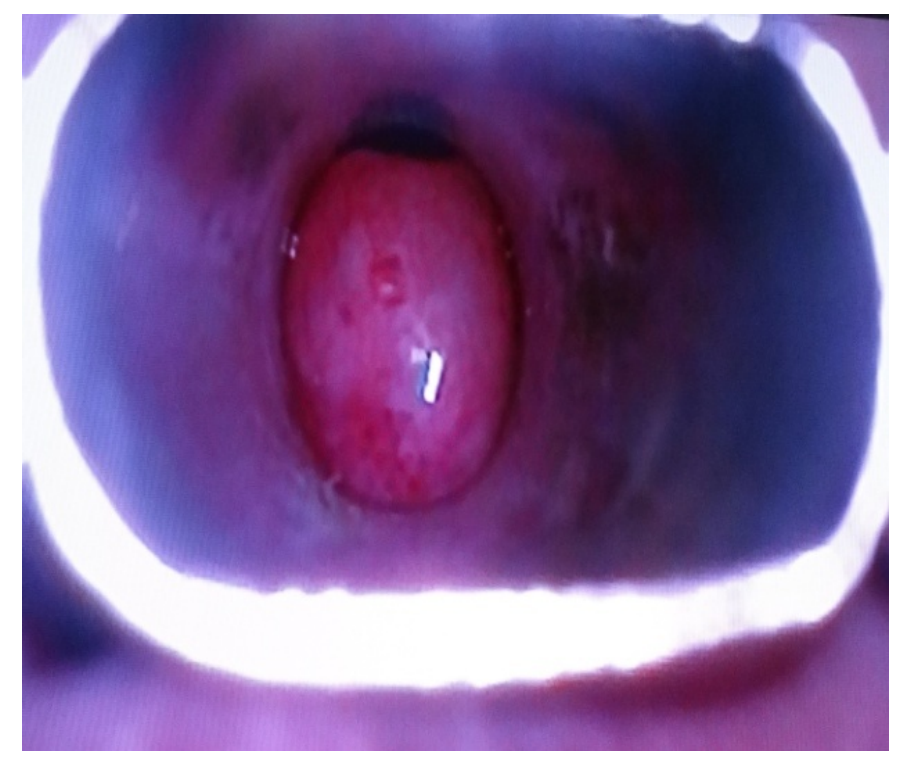

Figure 3. Superior view of tracheal mass.

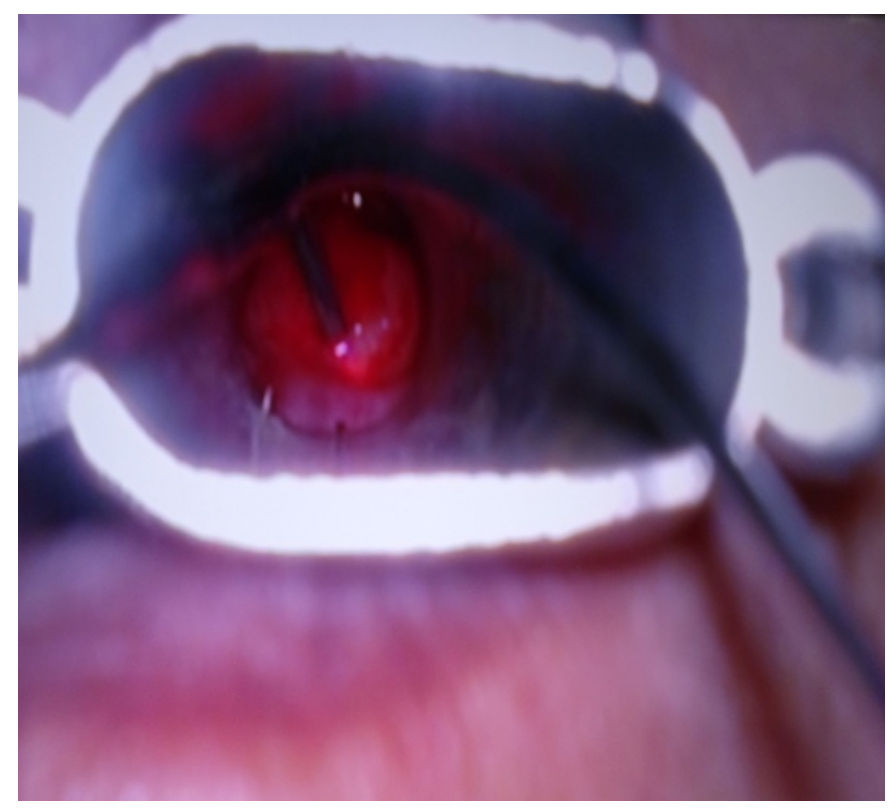

Figure 4. Intraoperative photograph showing excision of mass with diode laser. 


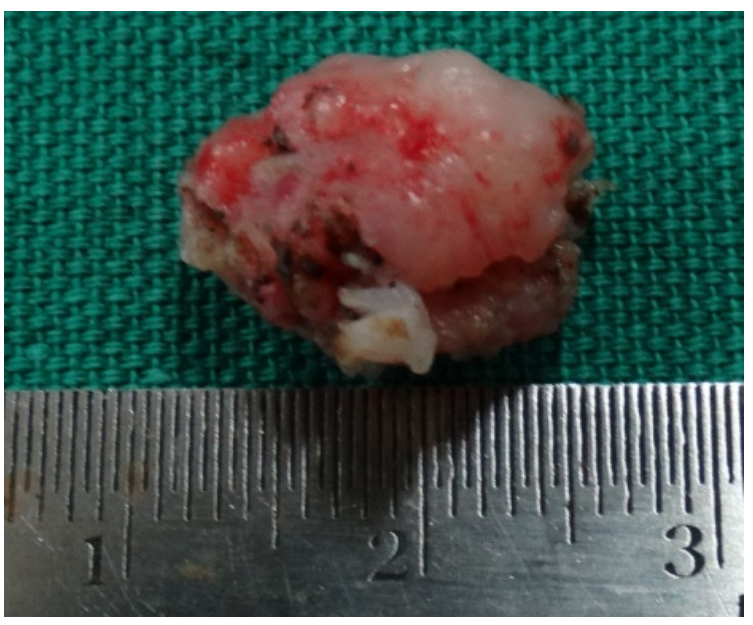

Figure 5. Showing the gross appearance of the tumor.

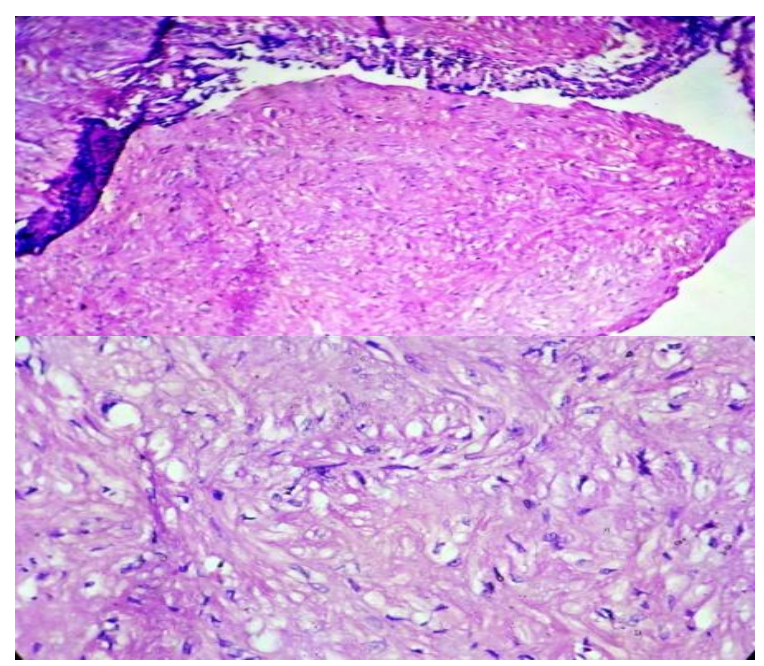

Figure 6. Microscopic appearance the tumor (low \& high resolution).

\section{Discussion}

Primary tumours of the trachea whether benign or malignant account for fewer than $0.1 \%$ of tumours. Malignant tumors are more common and often diagnosed early because of their rapid growth and onset of haemoptysis. Benign tumours are usually misdiagnosed as asthma or chronic lung disease, and diagnosis is delayed for months or years. Benign tumors of the trachea are rare and leiomyomas are much less common. Leiomyoma is a benign smooth muscle tumor most commonly associated with smooth muscle of the uterus or Gastro-Intestinal tract.

Leiomyoma is predominant in the third and fifth decades of age, with a mean age of 40.6 years for tracheal lesions which are more common in males [9]. It is thought to arise from either smooth muscle fibres surrounding the airway or smooth muscle fibres in blood vessels. Airway leiomyomas may arise anywhere from the supraglottic larynx to lung parenchyma [9] [10] though most commonly in the distal third of the membranous trachea [11].

These tumors grow as a smoothly contoured, polypoid mass and usually have a broad base [11]. Patients usually presents with dyspnoea, orthopnoea in the absence of cardiac disease, wheezing, stridor (symptoms of upper airway obstruction) or cough. Frequntly patients are misdiagnosed to have either asthma or chronic bronchitis. Ulceration and mucosal irritation caused by the lesion can result in cough with expectoration and haemoptysis [12]. 
They can be detected on plain radiographs of neck lateral view. CT scan neck \& chest helps in confirming the size and configuration and planning the airway management and surgical procedure. It also helps in ruling out contiguous lesions in other parts of aerodigestive tract. Final diagnosis is attained by direct bronchoscopic visualization and histopathologic examination.

Surgical Resection of the tumor is the treatment of choice depends on the location, size, width of the base of the tumor. The prognosis of leiomyoma is favorable if complete resection is achieved. Commonly performed techniques are tracheal sleeve resection, carinal resection, endoscopic resection, electrocoagulation, cryotherapy, Nd:YAG laser ablation. Segmental tracheal resection is recommended [11] but has the risk of anastomotic failure such as dehiscence or stenosis and requires more expertise. Different surgical and anaesthesiologic strategies are to be used, according to the location of the lesion. For tracheal tumors and main bronchial lesions that require carinal reconstruction, the operation should be performed using an anterior approach via median sternotomy in a supine position, and ventilation to be secured by inserting a flexible endotracheal tube into the distal airway using a separate ventilation circuit. For tumors located at the lobar bronchus or more distal locations, the usual segmentectomy or lobectomy is to be planned with a lateral decubitus position [6]. Bronchoscopic tumor excision can cause incomplete resection \& recurrence. In cases where wide resection was performed to achieve as large of a safety margin as was possible, bronchomediastinal fistula has been reported [6]. Death from bleeding has been reported during bronchoscopic excision [11].

In our case we went for endoscopic resection as the tumor was located intratracheally. Uniqueness in our case was the use of diode laser. Diode laser could be operated in a contact method which helped in resecting out the wide based tumor under direct vision minimizing damage to tracheal wall. The diode laser exhibits thermal effects using the "hot-tip" effect caused by heat accumulation at the end of the fiber, and produces a relatively thick coagulation layer on the treated surface [13]. This helped in aquiring a bloodless field which is most important in endoscopic resection.

Tissue penetration of a diode laser is less than that of the Nd:YAG laser, while the rate of heat generation is higher, resulting in deeper coagulation and more charring on the surface compared to the Nd:YAG laser [13]. This helps in protecting the posterior tracheal wall while ensuring the margins free. The width of the coagulation layer usually is in excess of $1.0 \mathrm{~mm}$ assuring wide resection and minimal recurrence. Laser was used in continuous and pulse mode in resecting out the tumour. Surgery was performed in continuous mode, but the pulse mode helped us to perform interventions with very high energy levels with a pulse duration in millisecond range. In this way, the thermal damage to the tissues does not progress deeper than 50 micron meters and carbonization is reduced to a minimum [13]. So for endoscopic resection of benign tumors like tracheal leiomyoma our approach with the use of diode laser was helpful in attaining wide resection with minimal intraoperative and post operative bleeding and minimizing damage to posterior tracheal wall.

\section{Conclusion}

Tracheal leiomyomas are rare tumors of trachea where the airway management and resection is difficult and requires expertise management. The use of diode laser in endoscopic resection helped us in attaining tumor free margins, better hemostasis and minimal damage to normal tissue.

\section{References}

[1] Macchiarini, P. (2006) Primary Tracheal Tumours. The Lancet Oncology, 7, 83-91. http://dx.doi.org/10.1016/S1470-2045(05)70541-6

[2] Gaissert, H.A., Grillo, H.C., Shadmehr, M.B., Wright, C.D., Gokhale, M., Wain, J.C. and Mathisen, D.J. (2006) Uncommon Primary Tracheal Tumors. Annals of Thoracic Surgery, 82, 268-273. http://dx.doi.org/10.1016/j.athoracsur.2006.01.065

[3] Borski, T.G., Stucker, F.L., Grafton, W.D. and Nathan, C.O. (2000) Leiomyoma of the Trachea: A Case Report and a Novel Surgical Approach. American Journal of Otolaryngology, 21, 119-121. http://dx.doi.org/10.1016/S0196-0709(00)85009-7

[4] Tamura, M., Murata, T., Kurumaya, H. and Ohta, Y. (2004) Leiomyoma of an Accessory Tracheal Bronchus. Annals of Thoracic Surgery, 78, 2163-2165. http://dx.doi.org/10.1016/S0003-4975(03)01500-5

[5] Sagawa, M., Inoue, K., Sato, M., Matsumura, Y., Kubo, H., et al. (1999) Successful Resection of Endotracheal Papillary Adenocarcinoma by Endoscopic Electrosurgery Using a New Snare: Report of a Case. Surgery Today, 29, 570- 
572. http://dx.doi.org/10.1007/BF02482357

[6] Park, J.S., Lee, M., Kim, H.K., Choi, Y.S., Kim, K., Kim, J., et al. (2011) Primary Leiomyoma of the Trachea, Bronchus, and Pulmonary Parenchyma-A Single-Institutional Experience. The European Journal of Cardio-Thoracic Surgery, 41, 41-45.

[7] Hooper, R.G. and Jackson, F.N. (1985) Endobronchial Electrocautery. Chest, 87, 712-714. http://dx.doi.org/10.1378/chest.87.6.712

[8] Homasson, J.R., Renault, P., Angebault, M., Bonniot, I.P. and Bell, N.J. (1986) Bronchoscopic Cryotherapy for Airway Strictures Caused by Tumors. Chest, 90, 159-164. http://dx.doi.org/10.1378/chest.90.2.159

[9] White, S.H., Ibrahim, N.B., Forrester-Wood, C.P. and Jeyasingham, K. (1985) Leiomyoma of the Lower Respiratory Tract. Thorax, 40, 306-311. http://dx.doi.org/10.1136/thx.40.4.306

[10] Xu, Y., Zhou, S. and Wang, S. (2008) Vascular Leiomyoma of the Larynx: A Rare Entity. Three Case Reports and Literature Review. ORL: Journal for Otorhinolaryngology and Its Related Specialties, 70, 264-267. http://dx.doi.org/10.1159/000133652

[11] Flint, P.W. and Cummings, C.W. (2010) Cummings Otolaryngology Head \& Neck Surgery. 5th Edition, Mosby Elsevier, Philadelphia.

[12] Foroughi, E. (1962) Leiomyoma of the Trachea. Chest Journal, 42, 230-232. http://dx.doi.org/10.1378/chest.42.2.230

[13] Malik, N.A. (2012) Textbook of Oral and Maxillofacial Surgery. 3rd Edition, Jaypee Brothers Medical Publishers, New Delhi, 949. 
Scientific Research Publishing (SCIRP) is one of the largest Open Access journal publishers. It is currently publishing more than 200 open access, online, peer-reviewed journals covering a wide range of academic disciplines. SCIRP serves the worldwide academic communities and contributes to the progress and application of science with its publication.

Other selected journals from SCIRP are listed as below. Submit your manuscript to us via either submit@scirp.org or Online Submission Portal.
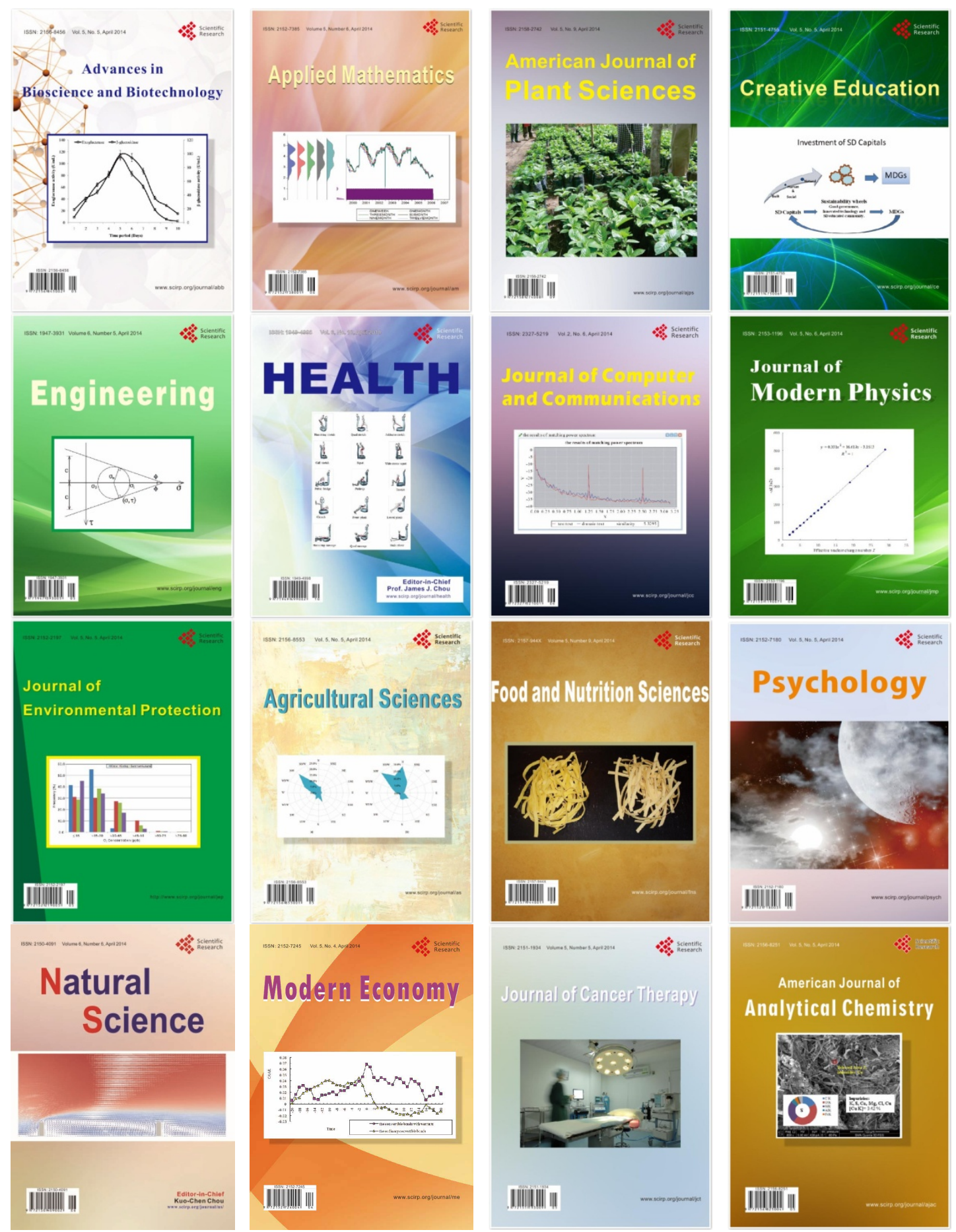